\title{
Seroprevalence and Risk Factors of the Helicobacter pylori Infection in Bukavu City in the Democratic Republic of Congo
}

\author{
Patrick de Jésus Ngoma1,2, Benjamin Longo-Mbenza1,3, Evariste Tshibangu-Kabamba4, \\ Bellarmin Matungo', David Lupande1,2, Christian Malu², Pitchou Kengibe ${ }^{2}$, \\ Antoine Tshimpi Wola Yaba², Charles Mbendi Nlombi², René Fiasse ${ }^{5}$, Dahma Hafid6, \\ Jeff Kabinda ${ }^{1}$, Yoshio Yamaoka ${ }^{5}$, Aliocha Nkodila ${ }^{3,7^{*}}$, Véronique Yvette Miendje Deyi ${ }^{6}$
}

\footnotetext{
${ }^{1}$ General Provincial Referral Hospital of Bukavu, Catholic University of Bukavu, Bukavu, Democratic Republic of the Congo ${ }^{2}$ Department of Hepato-Gastroenterology, University of Kinshasa ,Kinshasa, Democratic Republic of the Congo

${ }^{3}$ Lomo University of Research, Kinshasa, Democratic Republic of the Congo

${ }^{4}$ Department of Environmental and Preventive Medicine, Oita University, Yufu, Japan

${ }^{5}$ Department of Hepato-Gastroenterology, Saint-Luc University Clinics, Brussels, Belgium

${ }^{6}$ Department of Clinical Biology, Brugmann University Hospital, Brussels, Belgium

${ }^{7}$ Faculty of Family Medicine and Primary Health Care, Protestant University of Congo, Kinshasa,

Democratic Republic of the Congo

Email: ${ }^{*}$ kkodilaaliocha@gmail.com
}

How to cite this paper: de Jésus Ngoma, P., Longo-Mbenza, B., Tshibangu-Kabamba, E., Matungo, B., Lupande, D., Malu, C., Kengibe, P., Yaba, A.T.W., Nlombi, C.M., Fiasse, R., Hafid, D., Kabinda, J., Yamaoka, Y., Nkodila, A. and Deyi, V.Y.M. (2021) Seroprevalence and Risk Factors of the Helicobacter pylori Infection in Bukavu City in the Democratic Republic of Congo. Open Access Library Journal, 8: e8032. https://doi.org/10.4236/oalib.1108032

Received: September 30, 2021

Accepted: October 23, 2021

Published: October 26, 2021

Copyright $\odot 2021$ by author(s) and Open Access Library Inc.

This work is licensed under the Creative Commons Attribution International License (CC BY 4.0).

http://creativecommons.org/licenses/by/4.0/

\begin{abstract}
The prevalence of Helicobacter pylori (H. pylori) infection is high in Africa. However, local surveys are still needed to be conducted for filling up the gap existing in understanding the epidemiological situation of the infection within the continent. This study aimed to assess the seroprevalence of $H$. pylori and its determinant factors in Bukavu, the capital city of Southern Kivu Province in Eastern part of the Democratic Republic of Congo (DRC). A cross-sectional community-based study was conducted across the 3 communes of Bukavu. A two-stage cluster sampling process was performed at Health Area and Households levels by using a standard questionnaire addressing sociodemographic characteristics and gastrointestinal symptoms of participants. Sera samples were collected from each participant for the detection of anti- $H$. pylori IgG antibodies by an ELISA system. A logistic regression model was fitted to assess potential determinants of the anti- $H$. pylori positive serological status. Statistical analyses were conducted by SPSS software version $21\left(\mathrm{IBM}^{\circledR}\right.$, USA, 2012). The survey included 331 participants aged from 10 to 86 years old. The anti- $H$. pylori: seroprevalence was estimated at $89 \%$ [95\% CI: $84.9 \%-92.2 \%$ ]. Alcohol consumption increased the
\end{abstract}


risk of anti- $H$. pylori seropositivity by $6(\mathrm{OR}=5.73$ [95\% CI: $1.89-17.41$ ]; p $=0.002)$, while illiteracy $(\mathrm{OR}=0.41$ [95\% CI: $0.18-0.97] ; \mathrm{p}=0.043)$ and smoking (OR $=0.16$ [95\% CI: $0.04-0.65], \mathrm{p}=0.010)$ had paradoxical protective effect against anti- $H$. pylori seropositivity. The seroprevalence of $H$. $p y$ lori is very high in Bukavu. Identification of risk groups has the potential for supporting publish health issues needed for fighting against this infection. We recommend implementing appropriate sanitation and hygiene activities, health education programs, and further investigations for addressing this endemic infection locally.

\section{Subject Areas}

Biochemistry

\section{Keywords}

Helicobacter pylori, Seroprevalence, Risk Factors, Bukavu

\section{Introduction}

Helicobacter pylori ( $H$. pylori), a spiral-shaped gram-negative flagellated bacterium, colonizes the stomach of more than $50 \%$ of people worldwide. Its frequency varies widely with the geographical environment, ethnicity, age and socio-economic factors-it is high in developing countries and lower in developed countries [1] [2]. $H$. pylori infection is acquired in the majority of cases in childhood and, when not treated, leads to a lifelong infection [3]. Since its discovery in the early 1980s by Warren \& Marshall [4], H. pylori have been associated with several gastrointestinal diseases including chronic gastritis, peptic ulcers, gastric adenocarcinoma, and gastric MALT lymphomas [4] [5]. H. pylori infection is ubiquitous in sub-Saharan Africa where the prevalence is the highest observed [6]. However, available African data most often arise from hospital-based studies with substantial methodological limitations [7] [8] [9] [10]. Actually, these studies generally involve a small sample size of symptomatic patients likely missing to capture the majority of $H$. pylori carriers who remain asymptomatic [11] [12]. In DR Congo there are very little epidemiological data published on the $H$. pylori infection. In fact, a former study carried out in 1991 in eastern DRC in Katana in rural South Kivu, reported a prevalence of $H$. pylori of $90 \%$ in gastric biopsy samples [13]. In the city of Bukavu, the capital of the province, no data are available. Thus, this study aimed to estimate the seroprevalence of $\mathrm{H}$. pylori and identify its associated risk factors.

\section{Methods}

This study is reported following the Strengthening the reporting of observational studies in epidemiology (STROBE) Statement for Observational studies (Supplementary Appendix, STROBE Statement-Checklist) [14]. 


\subsection{Setting Study}

This study was carried out in Bukavu, the capital city of Southern Kivu province, located in the Eastern of the Democratic Republic of Congo. This city has 870,954 inhabitants and stretches over $60 \mathrm{~km}^{2}$ at an altitude of $1498 \mathrm{~m}$, on the Southwest coast of Kivu Lake. It is subdivided into 3 communes: Ibanda, Kadutu and Bagira corresponding to 3 Health Zones each divided into 12 health areas by the $\mathrm{Na}$ tional Health Administration System.

\subsection{Study Design}

A cross-sectional mass survey was conducted from April 15 to May 23, 2015. This survey targeted residents selected in households, regardless of gender or age, who had been living in the study area for at least 12 months. Study participants had to sign an informed consent form to be included in the study. A legal respondent adult had to sign the informed consent on the behalf of participants who were under 18 years old.

Since a prevalence of $70.8 \%$ has been reported in a neighboring population from Burundi [7], we estimated that a minimum sample size of 163 participants was deemed to be sufficient for estimating the prevalence in Bukavu city with its $95 \%$ confidence interval while reaching a precision of $5 \%$. A systematic random sampling scheme based on a two-stage cluster sampling process (the health area and the household levels) was applied for recruiting study participants. Therefore, the sample size of 163 was multiplied by 2 for reducing the clustering effect, reaching 326 . And by assuming a $10 \%$ loss of participants, the study targeted a sample size of 354 participants. Finally, 327 participants could be recruited.

\subsection{Data and Sample Collection}

The data collection was conducted by 12 investigators organized into three teams targeting each of the three Communes of the Bukavu city. Each team included a physician, a nurse, a laboratory technician, and a local community member who had been trained for the conduct of the survey. Activities performed by investigators consisted of identifying households to target, applying selection criteria for including participants in the study, conducting interviews based on a standard questionnaire and collecting biological samples in lines with good clinical practice requirements. Prior to the survey, the study questionnaire had been translated into Kiswahili, the local language, and successfully pre-tested on the field. For collecting biological samples, $3 \mathrm{ml}$ of whole blood were sampled from a vein of the right arm on each study participant and immediately put in an EDTA containing tube. Then, all the tubes with blood samples were transitorily kept into a cooler box before being transported to the Blood Bank Laboratory at the Provincial General Reference Hospital of Bukavu (PGRHB). At the PGRHB, the serum was extracted from each blood sample by centrifugation process and was stored at $-40^{\circ} \mathrm{C}$ until shipment under cold chain toward the Brugmann Hospital Laboratory in Brussels (Belgium) for biological analyses. 


\subsection{Biological Analyses}

A serological test for detecting $H$. pylori infection was carried out on each serum sample by using an ELISA kit (Euroimmun $\odot$, Lubek, Germany) processed under an Etimax 3000 analyzer (Diasorin $\odot$, Saluggia, Italy) and following the manufacturers' instructions. This technique allowed in vitro quantitative measurement of specific anti- $H$. pylori IgG antibodies, with a sensitivity and specificity of $100 \%$ according to the manufacturer. The result interpretation was made in agreement with criteria that had been set by the manufacturer:

- $\quad<16$ UR (Relative units)/ml: negative result;

- 16 - $21 \mathrm{UR} / \mathrm{ml}$ : doubtful result;

- $\geq 22 \mathrm{UR} / \mathrm{ml}$ : positive result.

\subsection{Study Variables}

The main variable of this study is the anti- $H$. pylori serological status which is categorical. Other variables were either categorical or numerical and included socio-demographic information (age, sex, address, number of people living in the household) and clinical features (alcohol consumption, tobacco consumption, level of promiscuity in daily life, drinking water source, and gastrointestinal symptoms) related to each study participant. Additional variables were operationally defined in the study as follows:

- A high level of promiscuity was defined as the presence of at least 3 people sharing one bedroom within a given household.

- The source of drinking water was considered as clean when water was from a tap (municipal water) or a harnessed water source, while non-potable drinking water was that coming from other types of sources (e.g. a lake, a river, a non-harnessed source or well).

- Based on the presence or the absence of gastrointestinal symptoms, two groups of participants were defined namely, symptomatic and asymptomatic participants.

\subsection{Risk of Bias}

Efforts to address potential sources of bias were made by the random sampling process likely avoiding selection bias in the study. Furthermore, eventual confounding factors were assessed statistically during the logistic regression modeling.

\subsection{Statistical Analysis}

All the data were recorded into an Excel database (Microsoft ${ }^{\circledR}$, USA, 2010) before being analyzed using the Statistical Package for Social Sciences (SPSS) software version $21\left(\mathrm{IBM}^{\circledR}\right.$, USA, 2012). The distributions of quantitative variables were summarized using medians with their respective interquartile ranges while qualitative variables were reported as absolute and relative frequencies for different categories. The comparison between proportions was performed using the Pearson Chi-square test or the corrected Yates' Chi-square test. The research for 
the factors associated with the anti-Helicobacter pylori positive serology was carried out by the logistic regression test in univariate analysis. When differences were observed between anti-Helicobacter pylori positive serology and the independent variables, the effect of potential confounders was investigated by logistic regression adjustment in multivariate analysis. Finally, the odds ratios (ORs) and their $95 \%$ confidence intervals (95\% CIs) were calculated to determine the degree of association between anti-Helicobacter pylori positive serology and the independent variables. A p value $<0.05$ was considered to be the threshold of statistical significance.

\subsection{Ethical Considerations}

This study was conducted in accordance with the standard ethical principles set out in the Declaration of Helsinki. The study protocol was approved by the ethical committee of the Catholic University of Bukavu. Free and informed consent was obtained from each study participant. The confidentiality of information collected from participants was observed. The collection of biological samples was carried out by trained and qualified investigators in fulfillment of standard good clinical practices (e.g. using disposable and sterile materials).

\section{Results}

\subsection{Study Participants}

A total of 331 participants was finally included, reaching a response rate of $93.5 \%(\mathrm{n}=331 / 354)$ compared to the targeted sample size.

\subsection{General Characteristics of the Study Participants}

The general characteristics of the study participants are presented in Table 1. We thus observed that participants were mainly young and female (sex ratio 2 women for $1 \mathrm{man}$ ). They had a low education level and low socioeconomic status. Almost all of them had access to drinking water and were non-smoker and tobacco users.

\subsection{H. pylori Seroprevalence in Bukavu}

The H. pylori seroprevalence rate in the general population of Bukavu was estimated at $89 \%$ [95\% CI: 84.9 - 92.2].

\subsection{Factors Predicting the risk of H. pylori Seropositivity in Bukavu}

The univariate analysis associating different variables of interest to the anti- $H$. pylori seropositivity is shown in Table 2 . It thus appears that the sex, the residence, the promiscuity, the number of people per household, the type of drinking water, the presence of digestive symptoms and the history of gastroscopy did not show any significant association with the anti- H. pylori seropositivity ( $\mathrm{p}>0.05)$. However, there was a significant association between the anti- $H$. pylori seropositivity and smoking, alcohol consumption as well as the university education level. 
The risk of anti- $H$. pylori seropositivity increased by more than 2 and more than 3 respectively with smoking and alcohol consumption, and with the university education level. After adjusting for confounding factors (smoking and residence), the logistic regression modelling shown in Table 3 identified significant

Table 1. Baseline characteristics of the study population.

\begin{tabular}{|c|c|c|c|}
\hline Characteristics & $\mathbf{n}$ & $\%$ & $\operatorname{Med}(\min -M a x)^{*}$ \\
\hline \multicolumn{4}{|l|}{ Sexe } \\
\hline Female & 215 & 65.0 & \\
\hline Male & 116 & 35.0 & \\
\hline Age (in year) & & & $30(10-86)$ \\
\hline$<20$ & 81 & 24.5 & \\
\hline $21-30$ & 88 & 26.6 & \\
\hline $31-40$ & 34 & 10.3 & \\
\hline $40-50$ & 22 & 6.6 & \\
\hline$>50$ & 106 & 32.0 & \\
\hline \multicolumn{4}{|l|}{ Profession } \\
\hline University or high school student & 118 & 39.1 & \\
\hline State civil worker & 19 & 6.3 & \\
\hline Worker in private sector & 109 & 36.1 & \\
\hline Unemployed & 56 & 18.5 & \\
\hline \multicolumn{4}{|l|}{ Address } \\
\hline Bagira & 72 & 21.8 & \\
\hline Ibanda & 145 & 43.8 & \\
\hline Kadutu & 114 & 34.4 & \\
\hline \multicolumn{4}{|l|}{ Education level } \\
\hline No education & 44 & 13.8 & \\
\hline Primary school level & 42 & 13.2 & \\
\hline High school level & 143 & 44.8 & \\
\hline Professional/technical level & 27 & 8.5 & \\
\hline College/University level & 63 & 19.7 & \\
\hline People in the household & & & $7(1-21)$ \\
\hline$<5$ & 101 & 30.9 & \\
\hline $6-10$ & 165 & 50.5 & \\
\hline$>10$ & 61 & 18.6 & \\
\hline Tobacco & 18 & 5.4 & \\
\hline Alcohol & 117 & 35.3 & \\
\hline Non-potable water drinking & 18 & 5.4 & \\
\hline History of endoscopy & 28 & 8.6 & \\
\hline
\end{tabular}

${ }^{*} \operatorname{Med}(\min -\max )=\operatorname{median}($ minimum and maximum $)$. 
Table 2. Distribution of Helicobacter pylori seropositivity among different categories of participants.

\begin{tabular}{|c|c|c|c|c|c|}
\hline \multirow{2}{*}{ Characteristics } & \multirow{2}{*}{$\mathbf{N}$} & \multicolumn{4}{|c|}{ H. pylori seropositivity } \\
\hline & & $\mathbf{n}$ & $\%$ & OR (IC-95\%) & $\mathrm{p}$ \\
\hline \multicolumn{6}{|l|}{ Sex } \\
\hline Female & 215 & 187 & 83.2 & 1 & \\
\hline Male & 116 & 107 & 86.2 & $1.8(0.8-3.9)$ & 0.15 \\
\hline \multicolumn{6}{|l|}{ Age } \\
\hline$\leq 20$ & 81 & 71 & 87.7 & $1.7(0.5-2.8)$ & 0.71 \\
\hline $21-30$ & 88 & 80 & 90.9 & $1.6(0.7-4.1)$ & 0.49 \\
\hline $31-40$ & 34 & 31 & 91.2 & $1.7(0.5-6.2)$ & $0.56^{*}$ \\
\hline $41-50$ & 22 & 21 & 95.5 & $3.5(0.4-27.7)$ & $0.30^{*}$ \\
\hline$>50$ & 106 & 91 & 85.8 & 1 & \\
\hline \multicolumn{6}{|l|}{ Tobacco } \\
\hline Yes & 18 & 17 & 94.4 & $2.4(1.2-3.3)$ & $0.04^{*}$ \\
\hline No & 313 & 277 & 88.5 & 1 & \\
\hline \multicolumn{6}{|l|}{ Alcohol } \\
\hline Yes & 117 & 112 & 95.7 & $3.9(1.4-11.8)$ & 0.003 \\
\hline No & 214 & 182 & 85 & 1 & \\
\hline \multicolumn{6}{|l|}{ Education level } \\
\hline No education & 44 & 35 & 79.5 & 1 & \\
\hline Primary & 42 & 37 & 88.1 & $1.9(0.6-6.2)$ & 0.28 \\
\hline Secondary & 143 & 127 & 88.8 & $2.0(0.9-4.5)$ & 0.11 \\
\hline Professional & 27 & 25 & 92.6 & $3.2(0.6-16.2)$ & $0.19^{*}$ \\
\hline University & 63 & 59 & 93.7 & $3.7(1.1-13.2)$ & $0.04^{*}$ \\
\hline \multicolumn{6}{|l|}{ Residency } \\
\hline Bagira & 72 & 66 & 91.7 & $1.8(0.6-5.2)$ & 0.24 \\
\hline Ibanda & 145 & 125 & 86.2 & 1 & \\
\hline Kadutu & 114 & 103 & 90.4 & $1.5(0.7-3.3)$ & 0.31 \\
\hline \multicolumn{6}{|l|}{ Promiscuity } \\
\hline Yes & 108 & 94 & 87 & $0.8(0.4-1.7)$ & 0.47 \\
\hline No & 223 & 200 & 89.7 & 1 & \\
\hline \multicolumn{6}{|l|}{ People in the household } \\
\hline$\leq 5$ & 101 & 89 & 88.1 & 1 & \\
\hline $6-10$ & 165 & 146 & 88.5 & $1.0(0.5-2.2)$ & 0.92 \\
\hline$>10$ & 61 & 55 & 90.2 & $1.2(0.4-3.5)$ & 0.67 \\
\hline \multicolumn{6}{|l|}{ Source of drinking water } \\
\hline Drinking water & 313 & 279 & 89.1 & 1 & \\
\hline No drinking water & 18 & 15 & 83.3 & $0.6(0.2-2.2)$ & $0.44^{*}$ \\
\hline
\end{tabular}




\section{Continued}

\begin{tabular}{lccccc}
\hline $\begin{array}{l}\text { Recurrent digestive symptoms } \\
\text { Yes }\end{array}$ & 248 & 218 & 87.9 & $0.7(0.3-1.6)$ & 0.36 \\
No & 83 & 76 & 91.6 & 1 & \\
Previous gastroscopy & & & & & 0.26 \\
Yes & 28 & 23 & 82.1 & $0.6(0.2-1.6)$ & \\
No & 296 & 264 & 89.2 & 1 & \\
\hline
\end{tabular}

${ }^{\star}$ Fisher exact.

Table 3. Final model of factors explaining the H. pylori seropositivity by a multivariate logistic regression*.

\begin{tabular}{ccc}
\hline Factor & Adjusted OR (CI 95\%) & p-Value \\
\hline Alcohol consumption & $5.73(1.89-17.41)$ & 0.002 \\
Yes & 1 & \\
No & & 0.043 \\
Education level & $2.5(1.1-5)$ & \\
Primary-university & 1 & 0.0006 \\
No education level & & \\
\hline
\end{tabular}

and independent predictors of anti- $H$. pylori seropositivity in the study population. Thus, the alcohol consumption increased by 6 , while the primary-university education level multiplied by 3 the risk of anti- $H$. pylori seropositivity in the final model (validity of the model: $\mathrm{p}<0.001$ ).

\section{Discussion}

This is the first study providing the data related to the epidemiology of $H$. pylori in the community living in Bukavu, the capital city of the Southern Kivu province in the Eastern part of the DRC. The H. pylori seroprevalence in Bukavu was thus estimated at $89 \%$ [95\% CI: 84.9 - 92.2]. A similar prevalence is often reported in serological surveys conducted in communities from emerging countries such as Turkey and China [14] [15] [16] or from developing countries such as Madagascar and Ethiopia [10] [17]. However, the observed prevalence is 2 to 9 times higher than that ranging from $10 \%$ to $30 \%$ often reported in populations from Western countries and [3] [18] [19]. The prevalence estimate observed in the current study is also higher to $H$. pylori infection rates reported during endoscopic surveys from Burundi (70.8\%) [7] and Rwanda (75.3\%) [8], two DRC's neighboring countries located close to Bukavu city. This very high $H$. pylori seroprevalence in Bukavu can be linked to several factors likely able to create conditions for a persisting high transmission level of $H$. pylori in the population. First, recurrent armed conflicts that have happened for more than 20 years in the Great Lakes Region where Bukavu city, Rwanda and Burundi have located re- 
gion, have forced huge population displacements since the 1990s in promiscuity and poor hygienic conditions favoring for $H$. pylori spread [20] [21] [22]. Moreover, many existing habits in local cultures may be additional risk factors for $H$. pylori contamination in the community. For instance, small children are often fed with feeds pre-chewed by their mothers-a practice capable of maintaining intra-familial H. pylori transmission [23]. Other local dietary habits are worthy to be mentioned, such as the fact that it is very common for a child to use the same cutlery with their parents when they are eating together, or for parents or elders to taste the cooled porridge of infants with the same spoonful [23]. On the other hand, an Iranian team, after isolating $H$. pylori living strains in milk and dairy products samples, has shown that the consumption of raw milk and its derivative products by humans could transmit $H$. pylori [24]. Bukavu is mainly occupied by the shi ethnic group, a pastoral ethnic, known for consuming unpasteurized cow's milk in their daily diet. One could then wonder whether this factor could play a certain role in the H. pylori epidemiology in the Bukavu area [25]. Furthermore, Bukavu is located in a region known to be endemic for cholera [26], a diarrheal infection established Megraud F. et al. [27] as increasing the risk of oral-fecal transmission of $H$. pylori.

We assessed different factors eventually associated with the $H$. pylori seropositivity in Bukavu. We thus observed that the $H$. pylori seroprevalence was higher among people aged 20 - 50, who were more active, inclined to excess alcohol and smoking consumption [28], with an infection rate of around $95.5 \%$ at 40 years old. The lowest prevalence rates were observed among people aged $<20$ and $>50$ years old $(86 \%)$. An increase of the H. pylori infection with age is often reported in the literature. The infection peak occurs in the forties in some studies [29] [30] but can vary according to studies, and generally concerns younger ages [9] [16] [31]. Globally, there is a tendency for the infection predominance to be in younger people in developing countries compared to developed countries [10]. The most common hypothesis explaining the increase in the prevalence of $H$. pylori as a function of age is the cohort effect [31] [32] [33] with the highest rate of infection among children born around 1965s in this study.

In the current study, men and women were equally infected with $H$. pylori (men: 86.2 versus women: $83.2 \%$ ) resulting in a sex ratio of 1.04 . There are controversies about the impact of sex on the seroprevalence of $H$. pylori. Actually, some studies support a neutral impact of sex [16] [32] [33] [34], while others show a predominance of $H$. pylori seropositivity in female [35] or male [9] [36] [37] [38]. Similar to the sex, there are controversies in the literature regarding a possible association between alcohol consumption or smoking, and H. pylori infection [9] [16] [32] [34] [35] [36] [37] [38]. Illustratively, while data from Japan [39], Sudan [39] and China [16] did not show any relationship between the $H$. pylori infection and tobacco, a recent meta-analysis of observational studies suggested that a reduction in $H$. pylori infection could be associated with moderate alcohol consumption [40]. Oppositely, the current study and other reports [23] [28] [39] show a rather significant association between excessive alcohol 
consumption and $H$. pylori seroprevalence. Furthermore, our observations showed that excess alcohol consumption increased by six the risk of having a positive anti $H$. pylori serology in Bukavu. Traditional alcoholic beverages are frequently consumed in a group of people who happily share their glasses as a form of solidarity in local understanding in the Bukavu area. This practice could be seen as an additional factor of oro-oral $H$. pylori transmission, which can be evoked to explain the association between seropositivity and alcohol consumption.

In the literature, the low level of education with ignorance is predictive of $H$. pylori infection [16] [41] [42] [43]. However, the current study shows that the low level of education, without financial resources along with excess alcohol consumption would be protective. In our country, the westernization of society concerns more the most educated barn of the population that copies many practices from Western societies. Thus a practice such as deep kissing currently enhanced by educated people might be having a role in the spread of $H$. pylori and may explain our observations. Indeed, it is established that the oral cavity hosts and can be a source of infection and transmission of $H$. pylori [43]. However, further studies are still needed to provide factual explanations for the epidemiological role eventually played by deep kissing in $H$. pylori transmission. Other possible factors such as gastroesophageal reflux should be considered.

Despite the absence of a significant association between the residence and the seroprevalence of $H$. pylori, the present study found a slightly lower seroprevalence in Ibanda commune $(86.2 \%)$, the highest rate observed in the city compared to the rate in the poor communes. Several authors in Africa have also not found a link between the seroprevalence of $H$. pylori and the rich or poor residing area [9] [10]. Even worse, Sathar M.A. et al. found no significant difference between urban and rural areas in South Africa [44].

Like Nurgalieva in Kazakhstan [45], the present study found no relationship between promiscuity and seroprevalence of $H$. pylori. However, several authors have found that promiscuity is closely related to $H$. pylori infection. This is the case of Füresz J. et al. among recruits of the Hungarian army [20], Kalaajieh WK et al. in Lebanon [21], or Malaty in Korea [22]. Unlike this study, different sources of water supply have been identified as potential reservoirs for acquiring the bacteria [46]. Thus, Nurgalieva ZZ found that the use of stream water was associated with a high prevalence of $H$. pylori [45]. As most of the literature data [46] gastric symptomatology was not associated with the seroprevalence of $H$. pylori in Bukavu. In addition, the history of upper gastrointestinal endoscopy has been described as a risk factor for $H$. pylori infection [32]. In the present study, however, the history of gastroscopy was not associated with $H$. pylori seropositivity.

\section{Conclusion}

In this study, the prevalence of $H$. pylori is high; it constitutes a public health problem in this city. This prevalence is associated with smoking, alcohol con- 
sumption and education level. To address this problem, appropriate epidemiological strategies should be drawn up and put in place with active involvement of the community, clinicians and policymakers.

\section{Authors' Contributions}

All authors contributed to data analysis, drafting or revising the article, have agreed on the journal to which the article will be submitted, gave final approval of the version to be published, and agree to be accountable for all aspects of the work.

\section{Conflicts of Interest}

The authors declare no conflicts of interest.

\section{References}

[1] Brown, L.M. (2000) Helicobacter pylori: Epidemiology and Routes of Transmission. Epidemiologic Reviews, 22, 283-297. https://doi.org/10.1093/oxfordjournals.epirev.a018040

[2] Bommelaer, G. and Stef, A. (2009) Ulcère gastroduodénal: Avant et après Helicobacter pylori. Gastroenterologie Clinique et Biologique, 33, 626-634. https://doi.org/10.1016/j.gcb.2009.07.004

[3] Bures, J., Kopacova, M., Skodova Fendrichova, M. and Rejchrt, S. (2011) Epidemiology of Helicobacter pylori Infection. Vnitrni Lekarstvi, 57, 993-999.

[4] Marshall, B. and Warren, J.R. (1984) Unidentified Curved Bacilli in the Stomach of Patients with Gastritis and Peptic Ulceration. The Lancet, 323, 1311-1315. https://doi.org/10.1016/S0140-6736(84)91816-6

[5] Suerbaum, S. and Michetti, P. (2002) Helicobacter pylori Infection. The New England Journal of Medicine, 347, 1175-1186. https://doi.org/10.1056/NEJMra020542

[6] Hooi, J.K., Lai, W.Y., Ng, W.K., et al. (2017) Global Prevalence of Helicobacter pylori Infection: Systematic Review and Meta-Analysis. Gastroenterology, 153, 420-429. https://doi.org/10.1053/j.gastro.2017.04.022

[7] Ntagirabiri, R., Harerimana, S., Makuraza, F., Ndirahisha, E., Kaze, H. and Moibeni, A. (2014) Helicobacter pylori au Burundi: Première évaluation de la prévalence en endoscopie et de l'éradication. Journal Africain d Hépato-Gastroentérologie, 8, 217-222. https://doi.org/10.1007/s12157-014-0567-3

[8] Walker, T.D., Karemera, M., Ngabonziza, F. and Kyamanywa, P. (2014) Helicobacter pylori Status and Associated Gastroscopic Diagnoses in a Tertiary Hospital Endoscopy Population in Rwanda. Transactions of the Royal Society of Tropical Medicine and Hygiene, 108, 305-307. https://doi.org/10.1093/trstmh/tru029

[9] Andoulo, F.A., Noah, D.N., Tagni-Sartre, M., Ndam, E.C.N. and Blackett, K.N. (2013) Epidémiologie de l'infection à Helicobacter pylori à Yaoundé: De la particularité à l'énigme Africaine. The Pan African Medical Journal, 16, Article ID: 115.

[10] Ramanampamonjy, R., Randria, M., Razafimahefa, S., Ratsimandisa, R., Rajaonarivelo, P. and Rajaona, H. (2007) Séroprévalence de l'infection due à Helicobacter pylori dans un échantillon de population malgache. Bulletin de la Société de Pathologie Exotique, 100, 57-60. 
[11] Malfertheiner, P., Megraud, F. and Morain, C.A. (2017) Management of Helicobacter pylori Infection-The Maastricht V/Florence Consensus Report. Gut, 66, 6-30. https://doi.org/10.1136/gutjnl-2016-312288

[12] Konturek, P.C., Konturek, S.J. and Brzozowki, T. (2006) Gastric Cancer and Helicobacter pylori Infection. Journal of Physiology and Pharmacology, 57, 51.

[13] Glupczynski, Y., Bourdeaux, L. and De Prez, C. (1991) Prevalence of Helicobacter pylori in Rural Kivu, Eastern Zaire: A Prospective Endoscopic Study. European Journal of Gastroenterology \& Hepatology, 3, 449-455.

[14] Von-Elm, E., Altman, D.G., Egger, M., et al. (2014) The Strengthening the Reporting of Observational Studies in Epidemiology (STROBE) Statement: Guidelines for Reporting Observational Studies. International Journal of Surgery, 12, 1495-1499. https://doi.org/10.1016/j.ijsu.2014.07.013

[15] Ozaydin, A.N. (1978) The Geographic Variance of Helicobacter pylori Infection in Europe and Its Impact on the Incidence of Gastric Cancer. Birth, 19, 7-9.

[16] Shi, R., Xu, S., Zhang, H., et al. (2008) Prevalence and Risk Factors for Helicobacter pylori Infection in Chinese Populations. Helicobacter, 13, 157-165.

https://doi.org/10.1111/j.1523-5378.2008.00586.x

[17] Tadesse, E., Daka, D., Yemane, D. and Shimelis, T. (2014) Seroprevalence of Helicobacter pylori Infection and Its Related Risk Factors in Symptomatic Patients in Southern Ethiopia. BMC Research Notes, 7, Article No. 834. https://doi.org/10.1186/1756-0500-7-834

[18] Eusebi, L.H., Zagari, R.M. and Bazzoli, F. (2014) Epidemiology of Helicobacter pylori Infection. Helicobacter, 19, 1-5. https://doi.org/10.1111/hel.12165

[19] Venneman, K., Huybrechts, I., Gunter, M.J., Vandendaele, L., Herrero, R. and Van Herck, K. (2018) The Epidemiology of Helicobacter pylori Infection in Europe and the Impact of Lifestyle on Its Natural Evolution toward Stomach Cancer after Infection: A Systematic Review. Helicobacter, 23, e12483. https://doi.org/10.1111/hel.12483

[20] Fürész, J., Lakatos, S., Németh, K., Fritz, P., Simon, L. and Kacserka, K. (2004) The Prevalence and Incidence of Helicobacter pylori Infections among Young Recruits during Service in the Hungarian Army. Helicobacter, 9, 77-80. https://doi.org/10.1111/j.1083-4389.2004.00200.x

[21] Kalaajieh, W.K., Chbani-Rima, A., Kassab, T.F. and Baghdadi, F.M. (2000) Infection à Helicobacter pylori au Liban Nord. Cahiers d'Études et de Recherches Francophones/Santé, 10, 31-35.

[22] Malaty, H.M., Kim, J.G., Kim, S.D. and Graham, D.Y. (1996) Prevalence of Helicobacter pylori Infection in Korean Children: Inverse Relation to Socioeconomic Status Despite a Uniformly High Prevalence in Adults. American Journal of Epidemiology, 143, 257-262. https://doi.org/10.1093/oxfordjournals.aje.a008736

[23] Smith, S., Jolaiya, T., Fowora, M., et al. (2014) Clinical and Socio-Demographic Risk Factors for Acquisition of Helicobacter pylori Infection in Nigeria. Asian Pacific Journal of Cancer Prevention, 19, 1851-1857.

[24] Mousavi, S., Dehkordi, F.S. and Rahimi, E. (2014) Virulence Factors and Antibiotic Resistance of Helicobacter pylori Isolated from Raw Milk and Unpasteurized Dairy Products in Iran. Journal of Venomous Animals and Toxins Including Tropical Diseases, 20, Article No. 51. https://doi.org/10.1186/1678-9199-20-51

[25] Deyi, V.M., Vanderpas, J., Bontems, P., et al. (2011) Marching Cohort of Helicobacter pylori Infection over Two Decades (1988-2007): Combined Effects of Secular Trend 
and Population Migration. Epidemiology and Infection, 139, 572-580. https://doi.org/10.1017/S095026881000110X

[26] Jeandron, A., Saidi, J.M., Kapama, A., et al. (2015) Water Supply Interruptions and Suspected Cholera Incidence: A Time-Series Regression in the Democratic Republic of the Congo. PLoS Medicine, 12, e1001893.

https://doi.org/10.1371/journal.pmed.1001893

[27] Megraud, F. (2003) Quand et comment s'infecte-t-on par Helicobacter pylori? Gastroenterologie Clinique et Biologique, 27, 374-379.

[28] Cardenas, V.M. and Graham, D.Y. (2005) Smoking and Helicobacter pylori Infection in a Sample of U.S. Adults. Epidemiology (Cambridge, Mass), 16, 586-590. https://doi.org/10.1097/01.ede.0000165365.52904.4a

[29] Kim, J.H., Kim, H.Y., Kim, N.Y., et al. (2001) Seroepidemiological Study of Helicobacter pylori Infection in Asymptomatic People in South Korea. Journal of Gastroenterology and Hepatology, 16, 969-975. https://doi.org/10.1046/j.1440-1746.2001.02568.x

[30] Salih, B.A. (2009) Helicobacter pylori Infection in Developing Countries: The Burden for How Long? The Saudi Journal of Gastroenterology, 15, 201-207. https://doi.org/10.4103/1319-3767.54743

[31] Essadik, A., Benomar, H., Rafik, I., et al. (2013) Aspects épidémiologiques et cliniques de l'infection à Helicobacter pylori à travers une étude marocaine. HEGEL, 3, 163-169.

[32] Graham, D.Y., Malaty, H.M., Evans, D.G., Evans, D.J., Klein, P.D. and Adam, E. (1991) Epidemiology of Helicobacter pylori in an Asymptomatic Population in the United States. Gastroenterology, 100, 1495-1501.

https://doi.org/10.1016/0016-5085(91)90644-Z

[33] Hunt, R., Xiao, S., Megraud, F., et al. (2011) Helicobacter pylori in Developing Countries. World Gastroenterology Organisation Global Guideline. Journal of Gastrointestinal and Liver Diseases, 20, 299-304.

[34] The, B.H., Lin, J.T., et al. (1994) Seroprevalence and Associated Risk Factors of Helicobacter pylori Infection in Taiwan. Anticancer Research, 14, 1389-1392.

[35] Alizadeh, A., Ansari, S., Ranjbar, M., et al. (2009) Seroprevalence of Helicobacter pylori in Nahavand: A Population-Based Study. Eastern Mediterranean Health Journal, 15, 129-135. https://doi.org/10.26719/2009.15.1.129

[36] Megraud, F., Brassens-Rabbe, M., Denis, F., Belbouri, A. and Hoa, D.Q. (1989) Seroepidemiology of Campylobacter pylori Infection in Various Populations. Journal of Clinical Microbiology, 27, 1870-1873.

[37] Longo-Mbenza, B., Nsenga, J.N., Mokondjimobe, E., et al. (2012) Helicobacter pylori Infection Is Identified as a Cardiovascular Risk Factor in Central Africans. Vascular Health and Risk Management, 8, 455-461. https://doi.org/10.2147/VHRM.S28680

[38] De Martel, C. and Parsonnet, J. (2006) Helicobacter pylori Infection and Gender: A Meta-Analysis of Population-Based Prevalence Surveys. Digestive Diseases and Sciences, 51, 2292-2301. https://doi.org/10.1007/s10620-006-9210-5

[39] Ogihara, A., Kikuchi, S., Hasegawa, A., et al. (2000) Relationship between Helicobacter pylori Infection and Smoking and Drinking Habits. Journal of Gastroenterology and Hepatology, 15, 271-276. https://doi.org/10.1046/j.1440-1746.2000.02077.x

[40] Liu, S.Y., Han, X.C., Sun, J., Chen, G.X., Zhou, X.Y. and Zhang, G.X. (2016) Alcohol Intake and Helicobacter pylori Infection: A Dose-Response Meta-Analysis of Observational Studies. Infectious Diseases, 48, 303-309.

https://doi.org/10.3109/23744235.2015.1113556 
[41] Naja, F., Kreiger, N. and Sullivan, T. (2007) Helicobacter pylori Infection in Ontario: Prevalence and Risk Factors. Canadian Journal of Gastroenterology and Hepatology, 21, Article ID: 462804. https://doi.org/10.1155/2007/462804

[42] Abdallah, T.M., Mohammed, H.B., Mohammed, M.H. and Ali, A.A. (2014) Sero-Prevalence and Factors Associated with Helicobacter pylori Infection in Eastern Sudan. Asian Pacific Journal of Tropical Disease, 4, 115-119. https://doi.org/10.1016/S2222-1808(14)60326-1

[43] Li, C., Musich, P., Ha, T., et al. (1995) High Prevalence of Helicobacter pylori in Saliva Demonstrated by a Novel PCR Assay. Journal of Clinical Pathology, 48, 662-666. https://doi.org/10.1136/jcp.48.7.662

[44] Sathar, M.A., Simjee, A.E., et al. (1994) Seroprevalence of Helicobacter pylori Infection in Natal/KwaZulu, South Africa. European Journal of Gastroenterology \& Hepatology, 6, 37-41.

[45] Nurgalieva, Z.Z., Malaty, H.M., Graham, D.Y., et al. (2002) Helicobacter pylori infection in Kazakhstan: Effect of Water Source and Household Hygiene. The American Journal of Tropical Medicine and Hygiene, 67, 201-206. https://doi.org/10.4269/ajtmh.2002.67.201

[46] Rolle-Kampczyk, U., Fritz, G., Diez, U., Lehmann, I., Richter, M. and Herbarth, O. (2004) Contaminated Well Water: A Risk Factor for Helicobacter pylori Infection. WIT Transactions on Ecology and the Environment, 77, 445-454. 